\title{
Characteristics of Mechanically Sorted Municipal Wastes and Their Suitability for Production of Refuse Derived Fuel
}

\author{
Dace Arina, Latvia University of Agriculture, Ausma Orupe, Institute of Physical Energetics
}

\begin{abstract}
The article presents the results of experimental work in the first waste mechanical Pre-treatment Centre in Latvia Daibe. The goal - to detect the main parameters for sorted waste parts and to compare them with parameters stated for refuse derived fuel (RDF) in a cement plant in Latvia (Cemex). Samples were taken in four fractions - coarse, medium, fine, metal. The parameters - upper, lower heating values, moisture, ash content, S, Cl, metals were determined. Results - coarse fraction has greater potential of the production of the RDF, but reduction of its content of $\mathrm{Cl}$ would be necessary.
\end{abstract}

Keywords - parameters of waste, pre-treatment, refuse derived fuel, cement plant

\section{INTRODUCTION}

The largest proportion of waste in the Baltic States is not sorted and is landfilled as shown by data of the Eurostat database [1] in Figure 1.

Practically, only about $20 \%$ of waste is sorted off even in cases when municipal solid waste (MSW) sorting from the source is introduced. At the same time, the EU requirements for sorting and recycling have been raised. The re-use and recycling of the EU Member States household waste materials shall be increased to at least of overall $50 \%$ by weight by 2020 [2]. This applies to other than household origins as far as these waste streams are similar to waste from households.

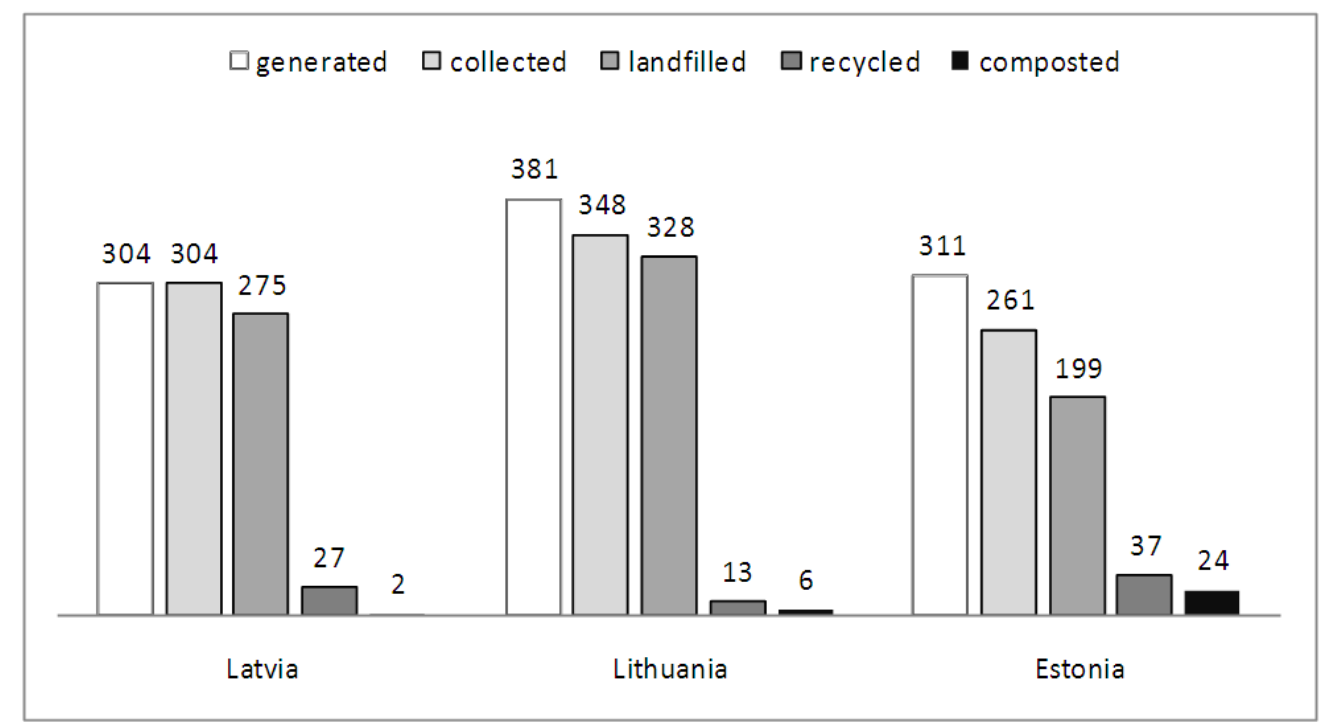

Fig.1. Generation, collection, landfilling and recycling of municipal waste in Baltic States (kg per capita in 2010) [1]

Therefore diverse waste recycling methods should be used to achieve these requirements. One of the methods is to produce refuse derived fuels (RDF) or solid recovered fuels (SRF). Conversion of waste into RDF or SRF serves two purposes: reduces the volume of waste sent to landfills, and provides alternative fuels for industries.

According to Rainer Stegmann only approximately $50 \%$ of the separately collected packaging material and the biowaste are recovered, though there is extensive waste prevention and recycling is applied in Germany [3].

The residual MSW is mechanically (including the separation of the high calorific value fraction) and biologically pre-treated before to landfilling in Germany [3].
Mechanical pre-treatment is one part of mechanical biological waste treatment (MBT). This includes four different process concepts in which mechanical, biological and thermal process stages with different objectives are combined with each other:

- Material Stream Separation,

- Mechanical-Biological Stabilization - with biological drying,

- Mechanical-Physical Stabilization - with thermal drying,

- Mechanical-Biological Pre-treatment prior to incineration (MBPT). 
The following main output streams are produced in MBT plants: solid recovered fuel, combustible fractions, which do not meet SRF quality, value added materials and landfill fractions. In plants based on separation, the mixed waste is separated by mechanical processing into:

- Concentrated high-calorific fraction for use as solid recovered fuel,

- Value added materials for material recycling (especially metals),

- Fraction with a depleted calorific value that is biologically treated and then landfilled [4].

The high quality recovered fuels (class SRF I) can be produced from commercial, construction, demolition and industrial waste, but quality class SRF II-III from household and commercial waste after source separation as shown by long term experience in Finland [5].

RDF can be differentiated from fossil fuels by the heterogeneous composition (e.g. size, higher inert material composition, volatile matter, chlorine, alkali and heavy metal content), lower calorific value, lower bulk density, lower energy conversion density. These properties have an influence on the ignition, combustion behavior, slag formation, corrosion potential and lastly on the energy conversion efficiency [6].

The SRF is an improved form of RDF and prepared according to the Latvian standard set in LVS EN 15359 technical specifications for the production and trade of SRF [7].

The buyer and the user and the quality of RDF or SRF should be clear while starting RDF or SRF production. Therefore the goal of work was to detect the main parameters for sorted waste parts and to compare them with parameters stated for alternative fuels by the cement plant Cemex located in the city of Brocēni. The eligibility of the tested parameters will give the possibility to reduce the disposed quantity of waste and use it as an energy source.

The SRFs are already used in cement kilns in the Cemex cement plant as a substitute for fossil fuels in Latvia. The alternative fuel specification for a cement plant defines that CEN/TS 15400, 15403, 15407, 15408, 15411, 15414, 15415, 15440 and CEN/TS 14775 should be used for measurements. The delivered material shall not contain disturbing parts and/or exceed the particle size above $70 \mathrm{~mm}$ (e.g. pieces of metal, stones, fibbers) in order to avoid damage to the conveying and dosing equipment in the cement plant. The delivered material must not contain dioxins, furans, PCBs or other hazardous organic components. The fuel to be used in the cement plant must have the waste code 191210 according to the European Waste Catalogue [8].

\section{MATERIAL AND METHODS}

Waste samples were taken from the Ziemelvidzeme solid municipal waste landfill Daibe which contains the first waste mechanical Pre-treatment Centre in Latvia and facilities for mechanical shredding, screening and separation of metal of the unsorted municipal waste. The shredder - model of Komptech -Terminator mobile 3400S F - throughput performance up to $50 \mathrm{t} \mathrm{h}^{-1}$; drum rpm.0-50 $\mathrm{mm}$. The screener (star screens) - model of Komptech Multistar L3-Flowerdisc throughput performance up to $180 \mathrm{~m}^{3} \mathrm{~h}^{-1}$ or $40 \mathrm{t} \mathrm{h}^{-1}$; screen sections: $0 / 10 \ldots 25 \mathrm{~mm} ; 10 \ldots 25 / 60 \ldots 80 \mathrm{~mm}$; >60...80 mm.

Twenty two municipalities together form the Ziemelvidzemes Region with a total area of 10411 square kilometers of which $98.7 \%$ is countryside and $1.7 \%$ is town territory (14 towns). The population - 186 thousands inhabitants: in the countryside 103 thousands, in towns 83 thousands. The system of the collection of sorted waste is widely developed in the Region unlike in the rest of the territory of Latvia.

Similarly to practice in Germany [9], the operation of the Pre-treatment Centre includes separation of the high calorific value fraction prior to landfilling. The absence of biowaste separation from household waste is the main difference of the Ziemelvidzeme Region and all Latvia from the practice in Germany and Finland, which is practiced only in the countryside in individual farms with individual composting.

Germany`s practice shows that after the separation of metal and RDF fraction (consisting mainly of paper and plastic) and after mechanical screening, the waste mass forms 2 parts: $<40-60 \mathrm{~mm}$, that is used for aerobic treatment or anaerobic digestion and $>40-60 \mathrm{~mm}$ used for biological drying and after that - energy recovery [9].

The experience of unsorted waste pre-treatment can be obtained from Lomellina, a waste to energy plant in Italy [10]. There is recyclables recovery and fuel preparation system. Each of three processing line is composed of a low velocity shredder, a primary drum screen (trommel) $(<60 \mathrm{~mm})$, a secondary drum screen $(<120 \mathrm{~mm})$, magnetic separators and a hammer mill. According to Pasi Makkonen and Arto Hotta [10], process is as following: The MSW, after the first shredding, is sent to the two step primary drum screen for separation into 3 streams: an organic fraction $(<60 \mathrm{~mm})$; a metals fraction $(60-120 \mathrm{~mm})$; a combustible fraction $(>120$ $\mathrm{mm})$. The remaining material is mixed to the combustible fraction and conveyed to the hammer mills. In the hammer mills the material is shredded to a particle size of $9 \mathrm{~cm}$ or less. The organic fraction is conveyed to the composting place where it is stabilized. The stabilized material (mainly paper and plastic) is sent to the secondary drum screen where materials over $2 \mathrm{~cm}$ in size, are recovered and conveyed to the $\mathrm{RDF}$ production stream. The remaining organic fraction can be refined using an air classifier for the separation of glass and other solid inert material. As a result the $60 \% \mathrm{RDF}, 1 \% \mathrm{Al}$, $2 \%$ metal, $10 \%$ compost and $6 \%$ glass are obtained from incoming municipal solid waste [10].

The sampling was carried out according to the Standard LVS CEN/TR 15310-(1-5):2007 [11]. Samples were taken from each fraction (excluding metal) according to the Standard LVS EN 14899:2011 [12]. The experimental truck load of the collected unsorted waste was chosen from the city in the summer season - waste from apartments, private houses and small companies; containers are removed 1-2 times per week.

The manual sampling from the conveyor belt was used as a sampling procedure [13]. A quantity of waste weighing $12300 \mathrm{~kg}$ is transported by conveyor belt at a speed at 15 tonnes per hour. Twenty-four samples were taken. The 
duration of each sampling interval was $2 \mathrm{~min}$. The sample size was $1-2 \mathrm{~kg}$.

The experimental research took place in the laboratory of the Institute of Physical Energetic in Latvia. The samples were weighed in the laboratory, dried at $103^{\circ} \mathrm{C}$ for 24 hours and weighed again. The morphological content was determined (sorted parts were weighed and respective weight percentage were calculated) in 10 parts - paper and cardboard (soft paper, journals, packing, wallpaper); plastic (soft and hard plastic); small particles, putrescible (kitchen waste, garden waste, miscellaneous small particles 0-25 $\mathrm{mm}$ ); hygiene (diapers and pads); textile; rubber (leather); wood; metal; glass; mineral.

In order to prepare representative samples for the laboratorial analyses after drying, the samples were manually sorted according to waste type and weighed. Then, according to percentage proportion of the combustible fraction samples of the laboratorial analyses were grained and formed. The following parameters: moisture, heating value, chlorine and sulphur content, ash, amount of heavy metals was determined according to the series of Standards - Characterization of waste.

\section{RESULTS AND DISCUSSION}

The results obtained present the content and the qualities of three municipal waste size fractions (coarse, medium, fine) of unsorted waste part within source separation waste system in the Region. The waste was coming from city households and commercial sector in the summer season and has undergone mechanical pre-treatment.

The mechanical pre-treatment of $12300 \mathrm{~kg}$ of unsorted municipal waste has produced following parts:

- Coarse fraction $3060 \mathrm{~kg}(25 \%)$;

- Medium fraction $5300 \mathrm{~kg}(43 \%)$;

- Fine fraction or putrescible $3620 \mathrm{~kg}(30 \%)$;

- Metal $200 \mathrm{~kg}(2 \%)$.

The average percentage distribution of the waste content and moisture of the dry mass is shown in tables I, II, III and IV.

TABLE I

DESCRIPTIVE STATISTICS OF COARSE FRACTION AVERAGE VALUE (\% OF DRY MASS) (95\% CONFIDENCE INTERVAL; N=11)

\begin{tabular}{|l|c|c|c|c|}
\hline $\begin{array}{l}\text { Content of } \\
\text { Waste }\end{array}$ & $\begin{array}{c}\text { Mean; Std. } \\
\text { Error }\end{array}$ & $\begin{array}{c}\text { Std. } \\
\text { Deviation }\end{array}$ & Min & Max \\
\hline $\begin{array}{l}\text { Paper and } \\
\text { cardboard }\end{array}$ & $46.1 \pm 8.87$ & 29.43 & 2.1 & 92.1 \\
\hline Plastic & $35.5 \pm 7.75$ & 25.72 & 4.8 & 77.9 \\
\hline $\begin{array}{l}\text { Small particles, } \\
\text { putrescible }\end{array}$ & $3.7 \pm 1.01$ & 3.36 & 0.0 & 11.1 \\
\hline $\begin{array}{l}\text { Hygiene } \\
\text { (diapers, pads) }\end{array}$ & $3.3 \pm 2.24$ & 7.42 & 0.0 & 22.2 \\
\hline Textile & $3.7 \pm 3.39$ & 11.25 & 0.0 & 37.5 \\
\hline Rubber & $6.2 \pm 4.25$ & 14.09 & 0.0 & 41.9 \\
\hline Wood & $0.01 \pm 0.04$ & 0.12 & 0.0 & 0.4 \\
\hline Metal & $1.2 \pm 0.86$ & 2.84 & 0.0 & 9.4 \\
\hline Mineral & $0.02 \pm 0.02$ & 0.06 & 0.0 & 0.2 \\
\hline
\end{tabular}

The content of coarse fraction is characterized by relatively large amount of (46\%) paper and cardboard and by $36 \%$ of plastic (both predominantly as packaging); with containing no glass waste. An insufficiently large size of the sample explains the large standard error for paper, plastic and rubber. Samples of this waste fraction contained not grained, large waste for an example foot wear, magazines, half of bucket, thus giving large part of percentage for some samples. According with Archer E. [14] usually refuse-derived fuel is recovered from the coarse fraction of materials going to the biological process stage in mechanical biological treatment (MTB) plants.

TABLE II

DESCRIPTIVE STATISTICS OF MEDIUM FRACTION AVERAGE VALUE (\% OF DRY MASS) (95\% CONFIDENCE INTERVAL; N=9)

\begin{tabular}{|l|c|c|c|c|}
\hline $\begin{array}{l}\text { Content of } \\
\text { Waste }\end{array}$ & $\begin{array}{c}\text { Mean; Std. } \\
\text { Error }\end{array}$ & $\begin{array}{c}\text { Std. } \\
\text { Deviation }\end{array}$ & Min & Max \\
\hline $\begin{array}{l}\text { Paper and } \\
\text { cardboard }\end{array}$ & $28.3 \pm 4.11$ & 12.32 & 13.0 & 48.3 \\
\hline Plastic & $25.4 \pm 3.93$ & 11.79 & 5.4 & 41.2 \\
\hline $\begin{array}{l}\text { Small particles, } \\
\text { putrescible }\end{array}$ & $14.1 \pm 2.98$ & 8.94 & 0.0 & 26.2 \\
\hline $\begin{array}{l}\text { Hygiene } \\
\text { (diapers, pads) }\end{array}$ & $2.0 \pm 0.75$ & 2.26 & 0.0 & 7.1 \\
\hline Textile & $0.7 \pm 0.31$ & 0.93 & 0.0 & 2.1 \\
\hline Rubber & $5.2 \pm 2.54$ & 7.61 & 0.0 & 22.9 \\
\hline Wood & $4.9 \pm 1.91$ & 5.73 & 0.0 & 17.2 \\
\hline Metal & $2.9 \pm 0.84$ & 2.53 & 0.0 & 6.1 \\
\hline Glass & $8.3 \pm 1.96$ & 5.89 & 2.3 & 18.1 \\
\hline Mineral & $8.1 \pm 3.42$ & 10.27 & 0.0 & 28.6 \\
\hline
\end{tabular}

The content of medium fraction is characterized by large waste diversity. The combustible part forms overall about 82 $\%$ of the waste of the medium fraction.

TABLE III

DESCRIPTIVE STATISTICS OF FINE FRACTION AVERAGE VALUE (\% OF DRY MASS) (95\% CONFIDENCE INTERVAL; N=9)

\begin{tabular}{|l|c|c|c|c|}
\hline $\begin{array}{l}\text { Content of } \\
\text { Waste }\end{array}$ & $\begin{array}{c}\text { Mean; Std. } \\
\text { Error }\end{array}$ & $\begin{array}{c}\text { Std. } \\
\text { Deviation }\end{array}$ & Min & Max \\
\hline $\begin{array}{l}\text { Paper and } \\
\text { cardboard }\end{array}$ & $1.6 \pm 0.50$ & 1.49 & 0.0 & 4.1 \\
\hline Plastic & $0.9 \pm 0.18$ & 0.53 & 0.0 & 1.7 \\
\hline $\begin{array}{l}\text { Small particles, } \\
\text { putrescible }\end{array}$ & $73.0 \pm 5.55$ & 16.66 & 42.0 & 93.5 \\
\hline Metal & $0.02 \pm 0.02$ & 0.07 & 0.0 & 0.2 \\
\hline Glass & $20.3 \pm 4.46$ & 13.38 & 1.9 & 42.3 \\
\hline Mineral & $4.2 \pm 1.58$ & 4.75 & 0.0 & 14.2 \\
\hline
\end{tabular}

The content of fine fraction is characterized by biologically degradable material (average $70 \%$ ): kitchen stuff, green waste from gardens and parks, partly decomposed paper and small particles (as sand and other material which can not be defined without chemical analyses), as well as about $27 \%$ of glass, ceramic and rocks; with no hygiene, textile, rubber, wood waste. After bio-treatment and stabilization it can be used as covering material. 
The household waste source sorting long term experience from Finland (by Wilén C. [5]) gives the following data:

- 5 bin separation scheme: recyclable paper (24\%), cardboard and paper packaging waste (3\%), biowaste $(27 \%)$, landfill waste $(32 \%)$; energy waste $(14 \%)-$ forming the following waste content for SRF production from the energy waste - fibre $49 \%$, plastics $35 \%$, biowaste $6 \%$, wood $4 \%$, other combustibles $4 \%$, glass and metal $2 \%$;

- 5 bin separation scheme: recyclable paper (29\%), biowaste $(20 \%)$, metal $(1 \%)$; glass $(1 \%)$, dry waste (49\%) - forming the following waste content for SRF production from the dry waste - fibre $23 \%$, plastics $14 \%$, biowaste $24 \%$, wood $4 \%$, other combustibles $20 \%$, rest fraction $3 \%$, other impurities $12 \%$;

- 2 bin separation scheme: wet waste (72\% biowaste, wet and dirty packages and paper), dry waste (28\%) forming the following waste content for SRF production from the dry waste - fibre $25 \%$, plastics $19 \%$, biowaste $29 \%$, wood $0 \%$, other combustibles $13 \%$, rest fraction $3 \%$, other impurities $11 \%$.

As paper, cardboard and some hygienic waste and textiles as absorbing moisture and plastic being relatively dry forms largest part of coarse fraction, the content of this fraction explains remarkable standard error of the content of the moisture in it. In that way moisture is greater if the largest part of the sample is formed of moisture absorbing waste.

TABLE IV

DESCRIPTIVE STATISTICS OF MOISTURE (\%) OF WASTE FRACTIONS (95\% CONFIDENCE INTERVAL)

\begin{tabular}{|l|c|c|c|c|}
\hline $\begin{array}{l}\text { Waste } \\
\text { Fraction }\end{array}$ & $\begin{array}{c}\text { Mean; } \\
\text { Std.Error }\end{array}$ & Std.Deviation & Min & Max \\
\hline $\begin{array}{l}\text { Coarse } \\
\text { fraction }\end{array}$ & $42.9 \pm 2.96$ & 12.20 & 12.6 & 62.2 \\
\hline $\begin{array}{l}\text { Medium } \\
\text { fraction }\end{array}$ & $49.2 \pm 1.55$ & 7.29 & 33.5 & 63.2 \\
\hline Fine fraction & $49.0 \pm 2.51$ & 8.70 & 35.2 & 62.8 \\
\hline
\end{tabular}

Table $\mathrm{V}$ presents data of the moisture and the municipal solid waste composition summarized in the literature $[10,15$, 16 and 17].

The moisture volume of the municipal solid waste is $31 \%$, $42 \%, 44 \%$ and $25-35 \%$ on average according to data in literature $[16,18,19]$.

Table VI contains average results of laboratorial analyses that are compared to the requirements of Cemex for SRF material.

TABLE V

UNDIFFERENTIATED MSW COMPOSITION AND WATER CONTENT OF DIFFERENT WASTE MATERIALS

\begin{tabular}{|c|c|c|c|c|}
\hline Composition & $\begin{array}{c}\text { Undifferentiated MSW } \\
\text { composition (\%) [15] }\end{array}$ & $\begin{array}{l}\text { Undifferentiated MSW } \\
\text { composition }(\%)[10]\end{array}$ & $\begin{array}{c}\text { Undifferentiated MSW } \\
\text { composition }(\%)[16,17]\end{array}$ & $\begin{array}{c}\text { Water content }(\%) \\
{[16,17]}\end{array}$ \\
\hline Paper and cardboard & 29 & 27.5 & 24.0 & 5 \\
\hline Plastic & 14 & 13.5 & 11.0 & 10 \\
\hline Glass & 3 & 8 & 8.0 & 5 \\
\hline Metals & 3 & 3.5 & 4.0 & 10 \\
\hline Textiles & \multirow[t]{3}{*}{2} & 3.5 & 4.0 & 0 \\
\hline Wood & & 3.5 & 4.0 & 0 \\
\hline Leather and rubber & & 6 (others) & 1.5 & 0 \\
\hline Food and garden waste (organic) & 40 & 27.5 & 31.0 & 85 \\
\hline Composite materials & - & - & 2.0 & 10 \\
\hline Ceramics and inerts & 3 & 5 (screenings, <20mm) & 9.0 & 0 \\
\hline Diapers and pads (hygiene) & 6 (other) & 2 & 1.5 & 90 \\
\hline
\end{tabular}

Finland's experience [5] is that, where the dry waste fraction from source separate household waste is used for the SRF production, the lower heating value is $13-16 \mathrm{MJ} \mathrm{kg}^{-1}$, moisture $25-35 \%$, ash $5-10 \%$, sulphur $0.1-0.2 \%$, chlorine $0.3-$ $1.0 \%$.
These data shows that the amount of moisture significantly decreases in the waste for RDF or SRF production by using source separation for biowaste of household.

TABLE VI

COMPARISON OF AVERAGE PARAMETERS OF WASTE SAMPLES FOR DRY MASS WITH CEMEX REQUIREMENTS

\begin{tabular}{|l|c|c|c|c|}
\hline & Coarse fraction & Medium fraction & Fine fraction & Cemex requirements \\
\hline $\begin{array}{l}\text { Lower Heating Value (as } \\
\text { received) MJ kg }\end{array}$ & $13.22 \pm 0.2$ & $10.56 \pm 0.2$ & $6.65 \pm 0.2$ & $>16$ \\
\hline $\begin{array}{l}\text { Upper Heating Value (Dry basis) } \\
\mathrm{MJ} \mathrm{kg}^{-1}\end{array}$ & $25.70 \pm 0.2$ & $23.67 \pm 0.2$ & $16.49 \pm 0.2$ & $>22$ \\
\hline Moisture (\%) & $42.9 \pm 0.5$ & $49.2 \pm 0,5$ & $49.0 \pm 0.5$ & $<25$ \\
\hline Ash content (dry basis) (\%) & $16.8 \pm 0.1$ & $14.9 \pm 0.1$ & $22.1 \pm 0.1$ & $<15$ \\
\hline
\end{tabular}




\begin{tabular}{|c|c|c|c|c|}
\hline S (\%) & $0.21 \pm 01$ & $0.27 \pm 0.1$ & $0.34 \pm 0.1$ & $<1.0$ \\
\hline $\mathrm{Cl}(\%)$ & $1.1 \pm 0.1$ & $4.1 \pm 0.1$ & $2.0 \pm 0.1$ & $<0.8$ \\
\hline Mercury (dry basis) $\mathrm{mg} \mathrm{kg}^{-1}$ & 0.50 & 0.45 & 0.66 & $<1.5$ \\
\hline Cadmium (dry basis) $\mathrm{mg} \mathrm{kg}^{-1}$ & 0.84 & 0.75 & 1.11 & $<9$ \\
\hline Thallium (dry basis) $\mathrm{m} \mathrm{kg}^{-1}$ & 0.34 & 0.30 & 0.44 & $<2$ \\
\hline Bromine (dry basis) M.-\% & 0.023 & 0.006 & 0.002 & $<0.25$ \\
\hline Iodine (dry basis) M.-\% & 0.001 & 0.001 & 0.001 & $<0.25$ \\
\hline Antimony (dry basis) $\mathrm{mg} \mathrm{kg}^{-1}$ & 5.376 & 5.811 & 0.663 & $<150$ \\
\hline Arsenic (dry basis) $\mathrm{mg} \mathrm{kg}^{-1}$ & 0.504 & 0.447 & 1.326 & $<20$ \\
\hline Chromium (dry basis) $\mathrm{mg} \mathrm{kg}^{-1}$ & 11.76 & 13.41 & 13.26 & $<150$ \\
\hline Cobalt (dry basis) $\mathrm{mg} \mathrm{kg}^{-1}$ & 1.68 & 1.49 & 2.21 & $<20$ \\
\hline Copper (dry basis) $\mathrm{mg} \mathrm{kg}^{-1}$ & 28.56 & 35.76 & 24.31 & $<500$ \\
\hline Lead (dry basis) $\mathrm{mg} \mathrm{kg}^{-1}$ & 60.48 & 62.58 & 16.35 & $<200$ \\
\hline Manganese (dry basis) $\mathrm{mg} \mathrm{kg}^{-1}$ & 47.04 & 87.91 & 112.71 & $<150$ \\
\hline Nickel (dry basis) $\mathrm{mg} \mathrm{kg}^{-1}$ & 5.04 & 4.47 & 8.84 & $<70$ \\
\hline Tin (dry basis) $\mathrm{mg} \mathrm{kg}^{-1}$ & 1.68 & 35.76 & 4.42 & $<50$ \\
\hline Vanadium (dry basis) $\mathrm{mg} \mathrm{kg}^{-1}$ & 8.4 & 7.45 & 22.1 & $<100$ \\
\hline
\end{tabular}

For all three fractions the lower heating value does not correspond to the Cemex requirements. It is because of large amount of moisture of the waste, as $98 \%$ and $82 \%$ of the coarse fraction and the medium fraction respectively consist of combustible materials. The average lower heating value $(6.65$ $\mathrm{MJ} \mathrm{KG}^{-1}$ ) of the fine fraction complies with the lower heating value of $6.86 \mathrm{MJ} \mathrm{kg}^{-1}$ from literature [16]. The higher heating value of the coarse fraction and the medium fraction corresponds to Cemex requirements.

The only medium fraction has corresponding ash content (up to $15 \%$ ). The large amount of paper and cardboard within the coarse fraction explains why it is not complying in regard to ash content. Whereas, the amount of biodegradable waste part explains it for the fine fraction.

The amount of sulphur and metals corresponds to Cemex requirements for all three fractions. According with Kai Sipilä, [19], the waste contains $0.1-0.2 \%$ of sulphur.

The amount of chlorine exceeds Cemex requirements for all three fractions; it is even 5 times higher for the medium fraction. This fact is explained by the plastic of polyvinylchloride (PVC) within this fraction (samples contained toys, PVC packaging and wire insulation materials). At present waste is formed from many goods produced at a time when the use of PVC was not restricted. Old paper and wallpaper could be the source of chlorine for the coarse fraction. According with Kai Sipilä, [19], the waste contains $0.3-1.0 \%$ of chlorine.

To decrease the amount of the moisture in the waste, and to increase the amount of waste for RDF or SRF production, it is advisable:

- To introduce the source separation system for the biowaste (including kitchen waste) - thus it is possible to obtain a qualitative mass of the biowaste that can be used for production of the compost or biogas.

- To perform (before mechanical pre-treatment) biological pre-treatment for all waste mass within closed reactors thus hygienizating the mass and improving the efficiency of the sorting. This is advisable to reduce the smell in pre-treatment centres of the unsorted waste located outside the landfill territory.

- It should be economically assessed whether the waste drying facilities can be added to the waste pretreatment cycle.

- To avoid the unnecessary increase of the moisture of the waste, the public should be informed accordingly about closing the covers of the waste containers.

- To activate source separation of glass, thus enlarging recovering possibilities for the fine fraction.

- To supplement the pre-treatment system with sorting by means of near-infrared spectroscopy (NIR) (according with Thiel, S.), thus reducing the amount of the polyvinyl chloride in the fine and medium fraction and contributing to the production of high-quality SRF. NIR is used on the one hand for ,positive sorting”, i.e. to selectively remove low-pollutant high-calorific material groups from different waste sub-streams. On the other hand it is used for ,negative sorting”, i.e. for the removal of unwanted materials [4]. The additional sorting line with a manual PVC plastic separation can be used as an alternative before cutting of the coarse fraction.

\section{CONCLUSIONS}

1. The coarse fraction is most suitable for the production of the RDF and SRF.

2. The coarse fraction needs additional treatment graining (hammer mill).

3. It is possible to increase the lower heating value of the coarse fraction and the medium fraction by using drying or biological pre-treatment followed by mechanical pretreatment.

4. It is necessary to analyse additional waste samples from other seasons to detect whether there is a significant difference between the proportions of the separated fractions and the results of the laboratory. It is necessary to continue research to define whether the amount of chlorine is always so high. 
5. To ensure more representation of waste content, the sample size should be increased for the coarse fraction.

6. The load from the regions in the countryside should be included in the analyses. It can have different waste content possibly a lower amount of bio-waste and a larger amount of packaging waste, thus increasing the proportion of the coarse fraction.

\section{ACKNOWLEDGEMENT}

The work was supported by the European Social Fund (ESF) project "Support for doctoral studies in LUA", agreement No: 2009/0180/1DP/1.1.2.1.2/09/IPIA/VIAA/017 for the doctoral research grant award to the first author.

\section{REFERENCES}

1. Eurostat, the statistical office of the European Union, Waste generation and treatment, 2010, [Online]. Available: http//epp.eurostat.ec.europa.eu/portal/page/portal/statistics/search_databas e. [Accessed: 02.03.2012.].

2. Directive 2008/98/Ec Of The European Parliament And Of The Council Of 19 November 2008 On Waste And Repealing Certain Directives Official Journal L 312, 22/11/2008 P.0003-0030. [Online]. Available: http://eur-lex.europa.eu. [Accessed: 05.03.2012].

3. Stegmann, R., "Mechanical Biological Pretreatment of Municipal Solid Waste", In: Tenth International Waste Management and Landfill Symposium, Sardinia, 2005.

4. Thiel, S., Thomé-Kozmiensky, J. K., Mechanical- Biological Pretreatment of Waste - Hope and Reality, pp.1-16, [Online]. Available: http://www.iswa.org/uploads/tx_iswaknowledgebase/Thiel.pdf. [Accessed: 13.05.2012].

5. Wilén, C., Salokoski P., Kurkela E., Sipilä, K., "Finnish expert report on best available techniques in energy production from solid recovered fuels", 2004, Finnish Environment Institute, pp.1-52. [Online]. Available: www.environment.fi/publications. [Accessed: 13.05.2012].

6. Beckmann, M., Ncube S., "Characterisation of Refuse Derived Fuels (RDF) in reference to the Fuel Technical Properties", In: Proceedings of the International Conference on Incineration and Thermal Treatment Technologies - IT3, 2007, Phoenix, USA, pp.1-15. [Online]. Available: http://tu-

dresden.de/die_tu_dresden/fakultaeten/fakultaet_maschinenwesen/iet/vws /Veroeffentlichungen/Beckmann_90-07/Be-104.pdf. Accessed: [13.05.2012].

7. National organization for standardisation, LVS EN 15359:2012 Solid recovered fuels - Specifications and classes.

8. The alternative fuel specification for cement plant Cemex, 2011, Available: www.cemex.lv. [Accessed: 02.03.2012.].

9. Ritzkowski, M., Heerenklage J., Stegmann R., "An overview on techniques and regulations of mechanical-biological pre-treatment of Municipal Solid Waste", Environmental Biotechnology, 2006, (2), pp.5768.

10. Makkonen, P., Hotta A., "Experiences of RDF Fluidized-Bed Combustion and Gasification, Emissions and Fuel Quality Aspects", In: Power production from Waste and Biomass IV, Espoo Finland, 2002, $\begin{array}{lll}\text { pp.185-209. [Online], Available: } & \end{array}$ www.vtt.fi/inf/pdf/symposiums/2002/s222.pdf. [Accessed: 01.03.2012.]

11. Latvian National organization for standardisation, LVS CEN/TR 153101:2007 Characterization of waste - Sampling of waste materials - Part 1:
Guidance on selection and application of criteria for sampling under various conditions.

12. Latvian National organization for standardisation, LVS EN 14899:2011 Characterization of waste - Sampling of waste materials - Framework for the preparation and application of a Sampling Plan.

13. Latvian National organization for standardisation, LVS EN 15442:2011 Solid recovered fuels - Methods for sampling

14. Archer, E., Baddeley, A., Klein, A., Schwage, J. \& Whiting, K. "Mechanical-Biological-Treatment: a Guide for Decision Makers Processes, Policies and Markets", Juniper Consultancy Services Ltd, Uley-Glucestershire, UK., 2005.

15. Papageorgiou A., Karagiannidis A., Barton John R., Kalogirou E., "Municipal solid waste management scenarios for Attica and their greenhouse gas emission impact”, Waste Management \& Research, 2009, 27, p.928-937.

16. Paolo S. Calabrò, The effect of separate collection of municipal solid waste on the lower calorific value of the residual waste, Waste Management \& Research, 2010; vol.28; p.754-758.

17. Tchobanoglous, G., Vigil, S.A.\&Theisen H., Integrated Solid Waste Management: Engineering Principles and Management Issues. McGrawHill Science Engineering, New York, ISBN 0070632375, 2003.

18. Luis F. Diaz, George M. Savage, Linda L. et al., Solid waste management for economically developing countries, ISWA, CalRecovery, Inc., 2005, 417 p.

19. Sipilä, K., "Overview of Finnish waste to energy R\&D programme", In: Power production from Waste and Biomass IV, Espoo Finland, 2002, 4145p., [Online], Available: www.vtt.fi/inf/pdf/symposiums/2002/s222.pdf. [Accessed: 01.03.2012.]

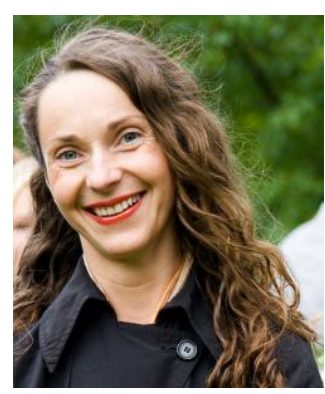

Dace Arina, Master Degree of Environmental Science (2002), University of Latvia, Faculty of Geography and Earth Sciences. Doctoral thesis: The analysis of options for waste biomass treatment and practical use in Latvia at the Latvia University of Agriculture.

A SCIENTIFIC ASSISTANT at the Institute of Physical Energetics in Latvia since 2002. A PROJECT ASSISTANT, COORDINATOR, ENVIRONMENTAL EXPERT, PURCHASE EXPERT for several waste management projects in Latvia since 2002. A member of the Waste Management Association of Latvia.

Address: Robezu Str. 13-9, Riga, LV-1004, Latvia.

Phone: +371 20250055

Fax: +371 67551361

E-mail: dace.arina@gmail.com

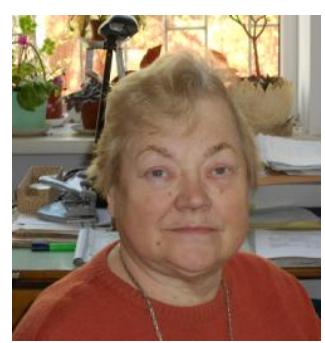

Ausma Orupe, Doctoral Degree of Chemistry, Council of Habilitation of Riga Technical University.

Employment: LEADING RESEARCHER of the Laboratory of Advanced Materials and Technologies of the Institute of Physical Energetics in Latvia.

Address: Kr. Barona Str. 122/2-8, Riga, Latvia. Phone: +37167558690

Fax: +371 67550839 